\title{
Choline Acetyltransferase and Acetylcholine Levels in Drosophila Melanogaster: A Study Using Two Temperature-sensitive Mutants ${ }^{1}$
}

\author{
PAUL M. SALVATERRA ${ }^{2}$ AND RICHARD E. MCCAMAN \\ Division of Neurosciences, Beckman Research Institute of the City of Hope, Duarte, California 91010
}

\begin{abstract}
Choline acetyltransferase (ChAT, acetyl-CoA-choline-Oacetyltransferase, EC 2.3.1.6) activity was measured in homogenates prepared from wild type (Canton S) and two temperature-sensitive presumed ChAT structural gene mutants (Cha ${ }^{t s 1}$ and $\mathrm{Cha}^{t s 2}$; originally described by Greenspan, R. (1980) J. Comp. Physiol. 137: 83-92) of Drosophila melanogaster. Wild type flies grown at $32^{\circ} \mathrm{C}$ for 12 or $24 \mathrm{hr}$ showed increased ChAT activity, whereas $\mathrm{Cha}^{\text {tst }}$ and Chats2 flies showed a progressive decrease in enzyme activity at $32^{\circ} \mathrm{C}$ (restrictive temperature) when compared to flies reared at $18^{\circ} \mathrm{C}$ (permissive temperature). Acetylcholine (ACh) and choline levels were determined in formic acid-acetone extracts of individual fly heads, and the ACh levels showed the same variation with time at $32^{\circ} \mathrm{C}$ as did the ChAT activity. In contrast, choline levels did not vary in any regular pattern. Acetylcholinesterase (EC 3.1.1.7) activity did not vary during heat treatment (except for Chat ${ }^{\text {s2 }}$ flies held at $32^{\circ} \mathrm{C}$ for 24 $\mathrm{hr}$, where a decrease was observed) indicating that this treatment may be specific for ChAT. We conclude that ChAT activity is strongly correlated with $\mathrm{ACh}$ levels in Drosophila heads and may thus have an important regulatory role in determining the levels of ACh available for physiological function.

We also report on the preliminary characterization of ChAT in both $\mathrm{Cha}^{\text {ts }}$ mutants and compare the biochemical properties to those of wild type enzyme. Isoelectric focusing profiles of ChAT from both Chats mutants revealed enzymes with altered patterns compared to wild type, indicating that the mutations are most probably in the structural gene. The in vitro thermolability of individual isoelectric point forms of ChAT were similar to that of total ChAT activity in a homogenate. The $k_{m}$ 's for choline and acetyl-CoA were similar for enzyme from wild type and $\mathrm{Cha}^{\text {tsi }}$ and differed only 2-fold for $\mathrm{Cha}^{\text {ts2 }}$. Immunoblot analysis of sodium dodecyl sulfate gels using a monoclonal antibody to Drosophila ChAT revealed only one 67,000-dalton band for either $\mathrm{Cha}^{{ }^{t s}}$ mutant, whereas wild type enzyme showed two bands reacting with antibody,
\end{abstract}

Received April 30, 1984; Revised August 6, 1984;

Accepted September 11, 1984

\footnotetext{
'We wish to thank R. Williamson for production of Cha mutants and invaluable genetic advice, Dr. G. Crawford for helpful discussions and antibody production, J. Stetzler and L. Correa for excellent technical assistance, Dr. J. Hall for making the Chats mutants available, and E. Hardy for preparing the manuscript. We gratefully acknowledge the support of National Institutes of Health Grants NS19482 and NS18857 and the Hurd Foundation.

${ }^{2}$ To whom correspondence should be addressed, at Division of Neurosciences, Beckman Research Institute of the City of Hope, 1450 East Duarte Road, Duarte, CA 91010.
}

one at 67,000 and the other at 54,000 daltons. Since the monoclonal antibody directly inhibits enzyme activity, it is likely that the epitope it recognizes is at or near the active site of the enzyme.

Drosophila melanogaster offers a favorable biological material for studying acetylcholine (ACh) metabolism in animals (Hall et al., 1979; Hall and Greenspan, 1979). ACh is thought to be the primary sensory neurotransmitter in arthropods (reviewed by Pitman, 1971; Gerschenfeld, 1973; Klemm, 1976), and high levels of the biosynthetic enzyme choline acetyltransferase (ChAT, EC 2.3.1.6) are present in insect nervous system (Dewhurst et al., 1970). The gene for ChAT has recently been identified and mapped in Drosophila, and two temperature-sensitive alleles have been isolated (Greenspan, 1980). The levels of ChAT activity have been manipulated in intact flies by altering the temperature, and the effects of these manipulations result in physiological and behavioral changes including abnormal electroretinograms, paralysis, and altered courtship patterns (Greenspan, 1980). These $\mathrm{Cha}^{t s}$ mutants have recently been used to identify a synapse using $\mathrm{ACh}$ as a neurotransmitter in the giant fiber pathway mediating the flight response (Gorczyca and Hall, 1983).

The relationship of ChAT activity to ACh levels in the nervous system is complex and controversial. The enzyme reaction involves acetylation of choline using acetyl-CoA. Since choline can also be utilized in other metabolic pathways, most notably for phospholipid synthesis (Jope and Jenden, 1979), regulation of ChAT activity could serve as an attractive and selective target for the in vivo control of ACh synthesis. Indeed, ChAT activity has been implicated as a regulatory step for $A C h$ production in a number of early studies (Kaita and Goldberg, 1969; Glover and Potter, 1971; Morris et al., 1971; Kuhar and Murrin, 1978). Others have argued against ChAT being a regulatory and/or rate-limiting step in ACh production on theoretical as well as practical grounds (Hebb, 1972; Krell and Goldberg, 1975; Hanbrich and Chippendale, 1977; Tuček, 1983) and have advanced a number of alternative hypotheses for the biochemical control point(s) regulating $A C h$ production.

The most popular alternative regulatory and/or rate-determining step involved in ACh production is the sodium- and energy-dependent high affinity choline transport system studied most extensively in mammalian brain synaptosome or slice preparations (Haga, 1971; Yamamura and Snyder, 1973; Kuhar and Murrin, 1978). This hypothesis has been supported by a number of studies which seem to implicate choline availability as the rate-limiting factor in ACh synthesis under a variety of conditions, including manipulation of systemic choline levels (Cohen and Wurtman, 1975; but see Wecker and Schmidt, 1979), inhibition of the high affinity choline transport system by hemicolinium-3 (Guyenet et al., 1973a, b) and the ability of high affinity choline transport capacity to change during nerve stimulation (Collier et al., 1983).

The relationship between high affinity choline transport and acetylation of choline by ChAT is also controversial. Several investigators 
have argued for a tight "physical" coupling (Barker and Mittag, 1975), whereas others have suggested that preferential choline acetylation, following high affinity transport, results from a "kinetic" coupling (Suszkiw and Pilar, 1976; Jope and Jenden, 1977). Other groups have been able to dissociate any apparent coupling between high affinity choline transport and acetylation by ChAT and thus argue for no direct regulatory relationship between these two processes (Marchbanks and Kessler, 1982).

In this paper we report the absolute levels of $\mathrm{ACh}$ and choline in wild type Canton S Drosophila melanogaster. We also establish a strong correlative relationship between ChAT activity and ACh levels using the two temperature-sensitive single gene mutants described by Greenspan (1980). We provide evidence for the structural gene nature of these mutants by showing their altered isoelectric focusing profiles. The in vitro thermolability of the individual isoelectric point (pl) forms of the enzymes from both $\mathrm{Cha}^{\text {ts }}$ mutants is similar to that reported in whole homogenates by Greenspan (1980). In addition, we report the kinetic parameters of ChAT from both mutants and propose a structural model to account for the various $\mathrm{pl}$ forms and immunologically identified polypeptides observed on Western blots of wild type and $\mathrm{Cha}^{\text {ts }}$ mutant proteins. A preliminary account of our work has been presented (Salvaterra et al., 1983; Salvaterra and McCaman, 1984).

\section{Materials and Methods}

Drosophila stocks. Canton $S$ flies were used as the wild type strain in these studies. Two temperature-sensitive ChAT alleles, $C h a^{t s 1}$ and $C h a^{i s 2}$, were obtained from Dr. Jeff Hall, Brandeis University. In some experiments the mutations were carried over wild type chromosomes with a deletion at the position of the Cha gene as described by Greenspan (1980). For other experiments, homozygous $\mathrm{Cha}^{\text {sti } 1}$ and $\mathrm{Cha}^{i s 2}$ stocks were prepared by crosses of mutant and wild type flies to neutralize the lethal mutations present on the Chats chromosomes. All stocks used for the studies of ACh levels, choline levels, and the effect of temperature on ChAT activity were reared for several generations at $18^{\circ} \mathrm{C}$ before initiation of the experiments.

Temperature shift experiments. Four- or 5-day-old flies of mixed sex (an equal number of male and female flies in most cases) were used. Individual vials contained 6 to 10 flies of known genotype and were kept on a 12-hr light/dark cycle during the course of the temperature shift experiments. For flies held at the restrictive temperature of $32^{\circ} \mathrm{C}$ for $12 \mathrm{hr}$, the first $6 \mathrm{hr}$ of dark were followed by $6 \mathrm{hr}$ of light. Flies held at $32^{\circ} \mathrm{C}$ for $24 \mathrm{hr}$ or at the permissive temperature of $18^{\circ} \mathrm{C}$ received $6 \mathrm{hr}$ of light, followed by $12 \mathrm{hr}$ of dark and 6 $\mathrm{hr}$ of light. Flies transferred from $32^{\circ} \mathrm{C}$ after $12 \mathrm{~h}$ to $18^{\circ} \mathrm{C}$ for $12 \mathrm{hr}$ underwent $6 \mathrm{hr}$ of light, $12 \mathrm{hr}$ of dark, and $6 \mathrm{hr}$ of light.

$A C h$ and choline levels. After incubation of flies at the restrictive or permissive temperature for the indicated times, groups of 6 to 10 flies were etherized and decapitated with a scalpel under a dissecting microscope. Individual fly heads were immediately placed in small glass homogenizers along with $100 \mu \mathrm{l}$ of $\mathrm{N}$ formic acid:acetone mixture $(15: 85 \mathrm{v} / \mathrm{V})$. After homogenization, the samples were briefly centrifuged (1000 $\times g$ for $5 \mathrm{~min}$ ),
Figure 1. ChAT activity and ACh levels in Drosophila heads after various times of growth at $32^{\circ} \mathrm{C}$. Bars represent the mean values for five individual 5-day-old flies for ACh determinations and triplicate assays of five pooled fly heads for ChAT activity. Zero hours at $32^{\circ}$ refers to flies grown exclusively at $18^{\circ} \mathrm{C}$, the permissive temperature for the mutants. Genotypes are: Canton S, Cha ${ }^{+} / \mathrm{Cha}^{+} ; T S_{1}$, Cha ${ }^{\text {st }} / \mathrm{Cha}^{t s 1} ; T S_{2} \mathrm{Cha}^{\text {ts2 }} /$ Cha ${ }^{t s 2}$. For further details see "Materials and Methods."
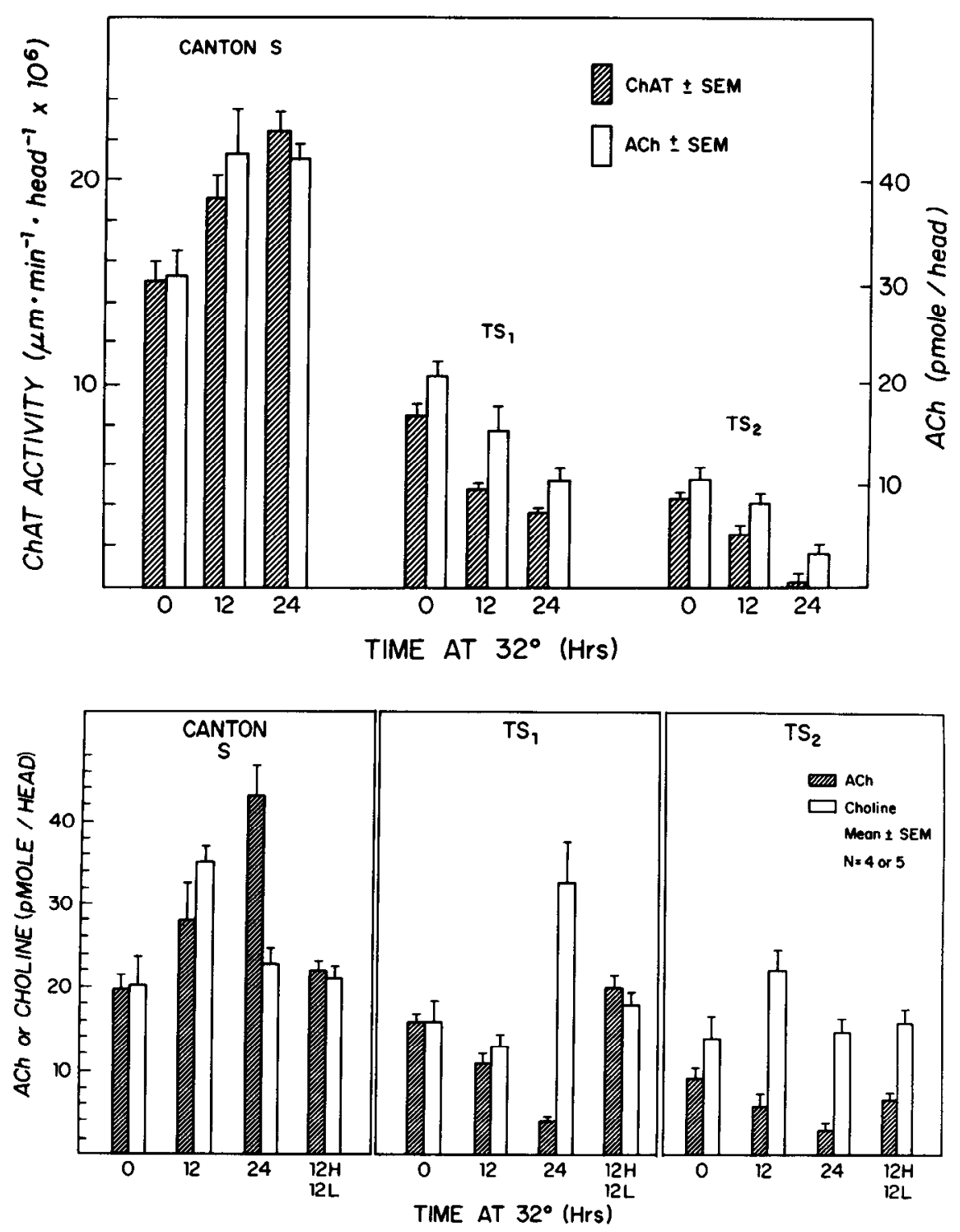

Figure 2. ACh and choline levels in Drosophila heads after various times of growth at $32^{\circ} \mathrm{C}$. Bars represent the mean values for four or five individual 6 day-old flies. The last set of bars in each panel $(12 \mathrm{H}$, 12L) refers to flies grown for $12 \mathrm{hr}$ at $32^{\circ} \mathrm{C}$ followed by $12 \mathrm{hr}$ at $18^{\circ} \mathrm{C}$ to test for recovery. For further details see Figure 1 and "Materials and Methods." 

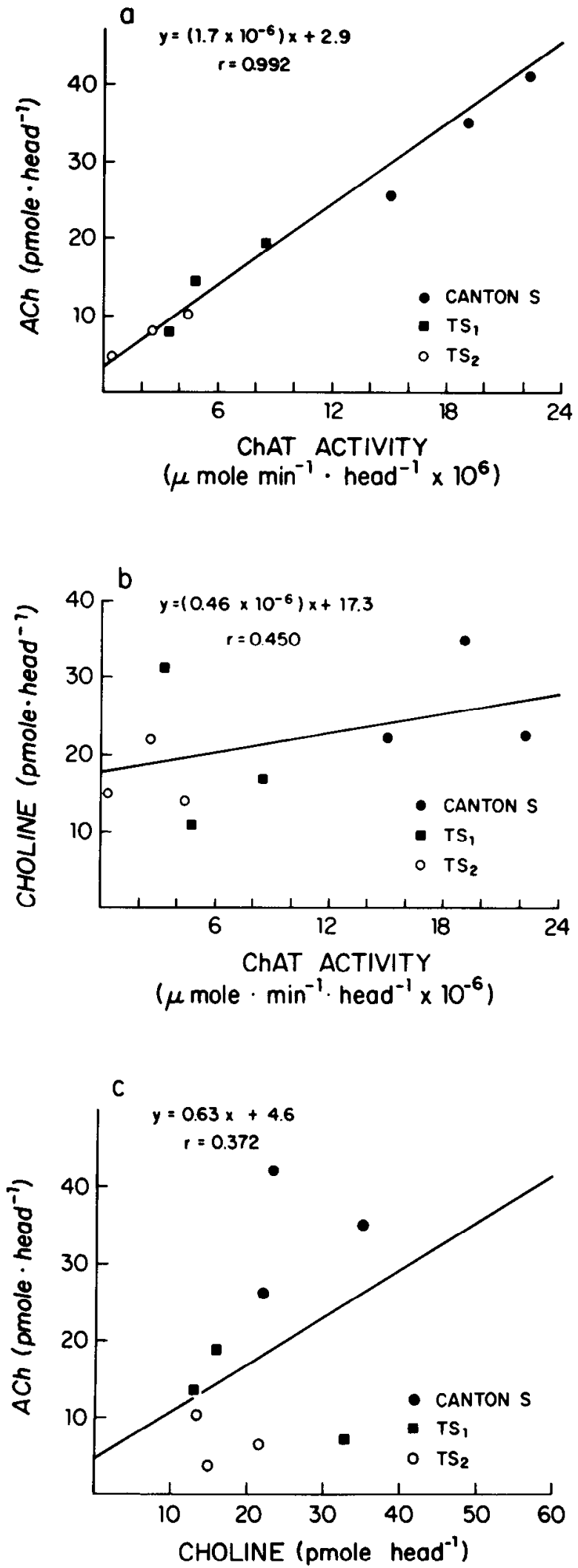

Figure 3. Relationship of ACh, choline, and ChAT activity. Data from Figures 1 and 2 were pooled and tested for correlation by least squares linear regression analysis. ACh versus ChAT activity is highly significant, whereas no significant correlation was found for choline versus ChAT or ACh versus choline.

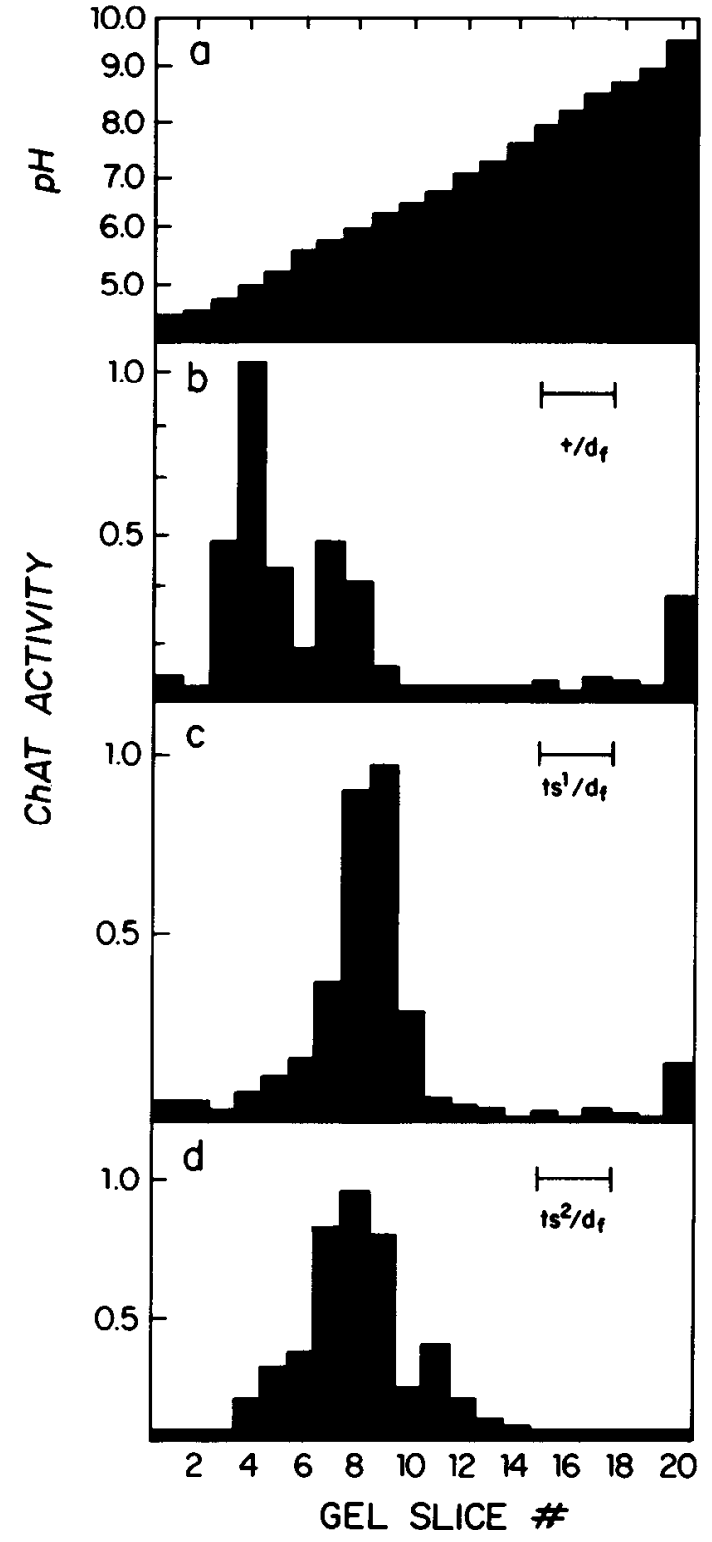

Figure 4. Thin layer isoelectric focusing of Drosophila ChAT. Samples were $50 \mu \mathrm{l}$ of freshly prepared homogenates applied directly to the gel in adjacent lanes at the position indicated by the line above the genotype. The gel was a $10 \times 12.5 \mathrm{~cm} 5 \%$ polyacrylamide slab containing $2 \% \mathrm{pH} 3$ to 10 Bio-Rad Biolyte Ampholines. Focusing was at $4^{\circ} \mathrm{C}$ for $120 \mathrm{~min}$ at a constant power of $7 \mathrm{~W}$. After focusing, the gel lanes were separated and sliced into $0.5-\mathrm{cm}$ sections. The $\mathrm{pH}(\mathrm{a})$ was determined on two separate lanes, as described under "Materials and Methods," and did not vary by more than $0.05 \mathrm{pH}$ unit. Enzyme activity was determined on duplicate aliquots of each gel slice and the highest value was arbitrarily set equal to 1 . Recovery of applied enzyme activity was $50 \%$ for Canton S $\mathrm{Cha}^{+} / \mathrm{Cha}^{+}(\mathrm{b})$ and approximately $20 \%$ for Cha ${ }^{t s 1} / C h a^{d f}(c)$ and $C h a^{t s 2} / C h a^{d f}(d)$.

and a measured aliquot $(80 \mu l)$ of the supernatant was removed and placed in a clean tube and reduced to dryness in a vacuum centrifuge. The sample at this point could be stored indefinitely at $-20^{\circ}$ or $-70^{\circ} \mathrm{C}$. The dried samples were reconstituted with $0.1 \mathrm{~N} \mathrm{HCl}(20 \mu l)$, and at least two aliquots, usually $4 \mu \mathrm{l}$, were removed from each sample for subsequent choline and ACh assays, respectively. The $\mathrm{HCl}$ solutions along with appropriate choline or ACh standards (freshly prepared in $0.1 \mathrm{~N} \mathrm{HCl}$ ) were again taken to dryness. The microradiometric assays for choline and ACh have been described previously (Goldberg and McCaman, 1973, 1974). The assays of the present study utilized the more recent modifications (McCaman and Stetzler, 1977) that provide an enhanced sensitivity, about 30 to $40 \mathrm{fmol}$. From preliminary tests we determined that choline or ACh measurements in single fly heads, or some smaller fraction thereof, did not require the use of tetraphenylboron 
TABLE I

Michaelis constants $\left(K_{m}\right)$ for wild type and mutant ChAT

\begin{tabular}{lcc}
\hline \multirow{2}{*}{ Genotype } & \multicolumn{2}{c}{$K_{m}{ }^{a}$} \\
\cline { 2 - 3 } & Choline & Acetyl-CoA \\
\hline Cha $^{+} / \mathrm{Cha}^{+}$ & $6.8 \pm 0.4 \times 10^{-3}$ & $1.1 \pm 0.2 \times 10^{-4}$ \\
Cha $^{t s} / \mathrm{Cha}^{t s 1}$ & $6.0 \pm 0.6 \times 10^{-3}$ & $1.6 \pm 0.8 \times 10^{-4}$ \\
$\mathrm{Cha}_{t s}{ }^{2} / \mathrm{Cha}_{t s}{ }^{2}$ & $3.4 \pm 1.1 \times 10^{-3}$ & $0.8 \pm 0.6 \times 10^{-4}$ \\
\hline
\end{tabular}

${ }^{a}$ Values were determined by least squares analysis of two LineweaverBurke plots of ChAT activity assayed at $37^{\circ} \mathrm{C}$ for $15 \mathrm{~min}$. At least five concentrations of choline (from $3 \times 10^{-2}$ to $2 \times 10^{-3} \mathrm{M}$ ) and acetyl-CoA (1.5 $\times 10^{-3}$ to $5.4 \times 10^{-5} \mathrm{M}$ ) were assayed in duplicate for each LineweaverBurke plot.

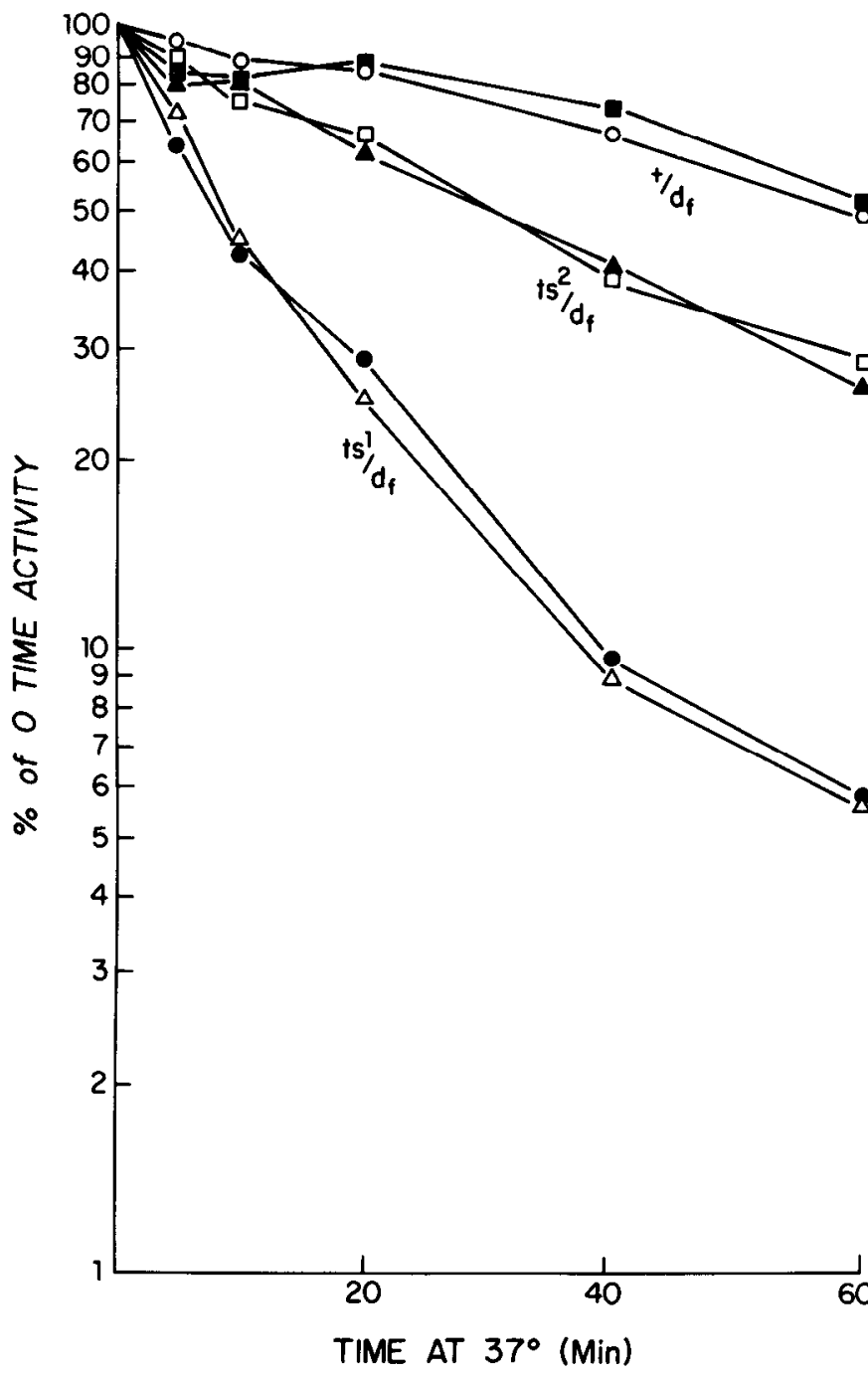

Figure 5. In vitro thermolability of different pl forms of ChAT. The different pl forms of ChAT isolated by polyacrylamide thin layer isoelectric focusing in Figure 4 were tested separately for in vitro thermolability. Samples were enzyme activity recovered from gel slices $3(\square)$ and $8(O)$ for Canton $S$, representing the low and high pl forms of the enzyme; gel slices $7(\boldsymbol{O})$ and $10(\Delta)$ representing the low and high $\mathrm{pH}$ limits of the single pl form observed for Cha ${ }^{i s i}$; and gel slices $7(\boldsymbol{\Delta})$ and $11(\square)$ representing the low and high pl forms for $\mathrm{Cha}^{t s 2}$. Samples were assayed in duplicate for $10 \mathrm{~mm}$ at $37^{\circ} \mathrm{C}$ as described under "Materials and Methods."

for prepurification of the tissue extract (Goldberg and McCaman, 1974). The amount of choline and ACh measured in a given extract was directly proportional to the amount of tissue over the range of sample.size used for this study $(0.002$ to $1 \mathrm{head})$. In two experiments we determined that individual brains dissected free of the head case in Drosophila Ringer (thanks to Dr.
TABLE ॥

Isoelectric points of wild type and mutant ChAT

Samples included homogenates (either fresh or frozen) or polyethylene glycol precipitates and were isoelectrically focused as described under "Materials and Methods" using either a pH 4 to 6 or pH 3 to 10 gradient. No systematic differences were observed in the type of sample or stored-versus-fresh samples; therefore, all data have been pooled.

\begin{tabular}{ll}
\hline \multicolumn{1}{c}{ Genotype } & \multicolumn{1}{c}{$\mathrm{pl}^{\mathrm{a}}$} \\
\hline $\mathrm{Cha}^{+} /$Cha $^{+}$ & $4.91 \pm 0.15(9){ }^{D} 5.49 \pm 0.11(9)$ \\
$\mathrm{Cha}^{t s 1} /$ Cha $^{t s 1}$ & $5.46 \pm 0.18(9)$ \\
Cha $^{t s 2} /$ Cha $^{t s 2}$ & $5.58 \pm 0.17(4), 6.24 \pm 0.24(4)$ \\
\hline
\end{tabular}

${ }^{a}$ Values represent the mean \pm the standard error.

${ }^{\circ}$ Numbers in parentheses, number of samples.

K. Ikeda) contained the same amount of ACh as measured in homogenates of whole heads. In five comparative experiments with Canton $S$ flies, no significant differences were detected between male versus female flies raised under identical conditions. Only a few preliminary assays were peformed on whole flies, and from these we concluded that: (a) measurement of choline and $\mathrm{ACh}$ in these samples required the more cumbersome prepurification procedure with tetraphenylboron, and $(b)$ heads appear to contain about $15 \%$ and $35 \%$ of the choline and $A C h$, respectively, present in whole flies.

ChAT and acetylcholinesterase (AChE) activity. For measurements of enzyme activity to be correlated with $\mathrm{ACh}$ and choline levels, parallel groups of 6 to 12 flies were etherized and decapitated; then, the heads were pooled and homogenized at $4^{\circ} \mathrm{C}$ in $200 \mu \mathrm{l}$ of $50 \mathrm{~mm}$ Tris, $\mathrm{pH} 7.4,0.1 \mathrm{M} \mathrm{NaCl}, 0.5 \%$ Triton $\mathrm{X}-100$, using a motor-driven glass-Teflon homogenizer. ChAT activity was determined in triplicate on an aliquot of homogenate by the procedure of Fonnum (1975), as described by Slemmon et al. (1982). AChE activity was determined in separate groups of flies by the assay of Ellman et al. (1961), using acetylthiolcholine substrate. All enzyme assays were performed at $37^{\circ} \mathrm{C}$ under conditions of linearity with time. For ChAT activity in the Chatsi and $\mathrm{Cha}^{t{ }^{t 2}}$ mutants, the activity present at zero time was calculated by correcting for the loss of enzyme activity during the assay incubation at $37^{\circ} \mathrm{C}$ (usually 10 to $30 \mathrm{~min}$ ).

Isoelectric focusing. Isoelectric focusing of wild type and mutant ChAT was performed using a thin layer polyacrylamide slab gel and the Bio-Rad 1415 electrophoresis system. The gel $(10 \times 12.5 \mathrm{~cm})$ contained $5 \%$ acrylamide, $0.15 \% N, N^{\prime}$-methylene-bisacrylamide, and $2 \%$ Biolyte Ampholines (either $\mathrm{pH} 3$ to 10 or $\mathrm{pH} 4$ to 6 ). Samples (25 to $50 \mu$ il) of either homogenates or redissolved polyethylene glycol precipitates (as described by Slemmon et al., .1982) were applied directly to the gel near the cathode. Gels were focused at $4^{\circ} \mathrm{C}$ using a constant power of 6 to $10 \mathrm{~W}$ for 90 to $180 \mathrm{~min}$ Immediately after focusing. gel lanes were separated and sliced into $0.5-\mathrm{cm}$ sections. The individual gel sections were soaked in either $1 \mathrm{ml}$ of $1 \mathrm{M} \mathrm{NaCl}$ for $\mathrm{pH}$ determination at $4^{\circ} \mathrm{C}$ or $250 \mu$ of $50 \mathrm{mM} \mathrm{PO}_{4}$ buffer, $\mathrm{pH} 7.4$, containing $0.05 \%$ Triton X-100, 1 mM dithiothreitol, and $1 \%$ bovine serum albumin for enzyme assay on the following day. Twenty-microliter aliquots of the latter samples were assayed in duplicate or triplicate for ChAT activity, and recovery of applied enzyme activity ranged from 10 to $50 \%$.

Immunoblotting. DEAE-purified or redissolved polyethylene glycol precipitates (Slemmon et al., 1982) were electrophoresed in SDS-polyacrylamide slab gels (Laemmli, 1970). The electrophoresed proteins were transferred to nitrocellulose sheets, as described by Towbin et al. (1979), using 250 to 350 $\mathrm{mA}$ of current for 12 to $18 \mathrm{hr}$. The nitrocellulose blots were stained for protein using $0.1 \%$ amido black or antigen as described. For detection of ChAT antigen, nitrocellulose blots were first soaked in $3 \%$ gelatin or bovine serum albumin in $50 \mathrm{~mm}$ Tris- $150 \mathrm{~mm} \mathrm{NaCl}, \mathrm{pH} 7.4$, for $1 \mathrm{hr}$ at $37^{\circ} \mathrm{C}$ to block nonspecific binding of antibodies. Following several rinses in Tris- $\mathrm{NaCl}$, the nitrocellulose was incubated in a $10 \mu \mathrm{g} / \mathrm{ml}$ solution of monoclonal antiDrosophila ChAT antibody (Crawford et al., 1982) in $50 \mathrm{~mm}$ Tris, pH 7.4, 150 $\mathrm{mm} \mathrm{NaCl}, 5 \mathrm{~mm}$ EDTA, $0.5 \%$ Nonident P-40 for at least $2 \mathrm{hr}$ at room temperature. The antibody solution was removed and the nitrocellulose was rinsed with several changes of $50 \mathrm{mM}$ Tris, $\mathrm{pH} 7.4,150 \mathrm{mM} \mathrm{NaCl}, 5 \mathrm{~mm}$ EDTA, $0.5 \%$ Triton X-100. Anti-ChAT antibody was detected by incubating first in a rabbit anti-mouse igG antibody and rinsing as above, followed by 1 $\times 10^{6} \mathrm{cpm}$ of $\left.{ }^{125}\right]$ protein $\mathrm{A}$. The nitrocellulose was air-dried and radioautographed at $-80^{\circ} \mathrm{C}$ using Kodak x-ray film and a DuPont Cronex intensifying screen.

\section{Results}

ChAT, ACh, and choline. Figure 1 shows the levels of ChAT activity and $A C h$ measured in 5-day-old homozygous Canton $S$ and 

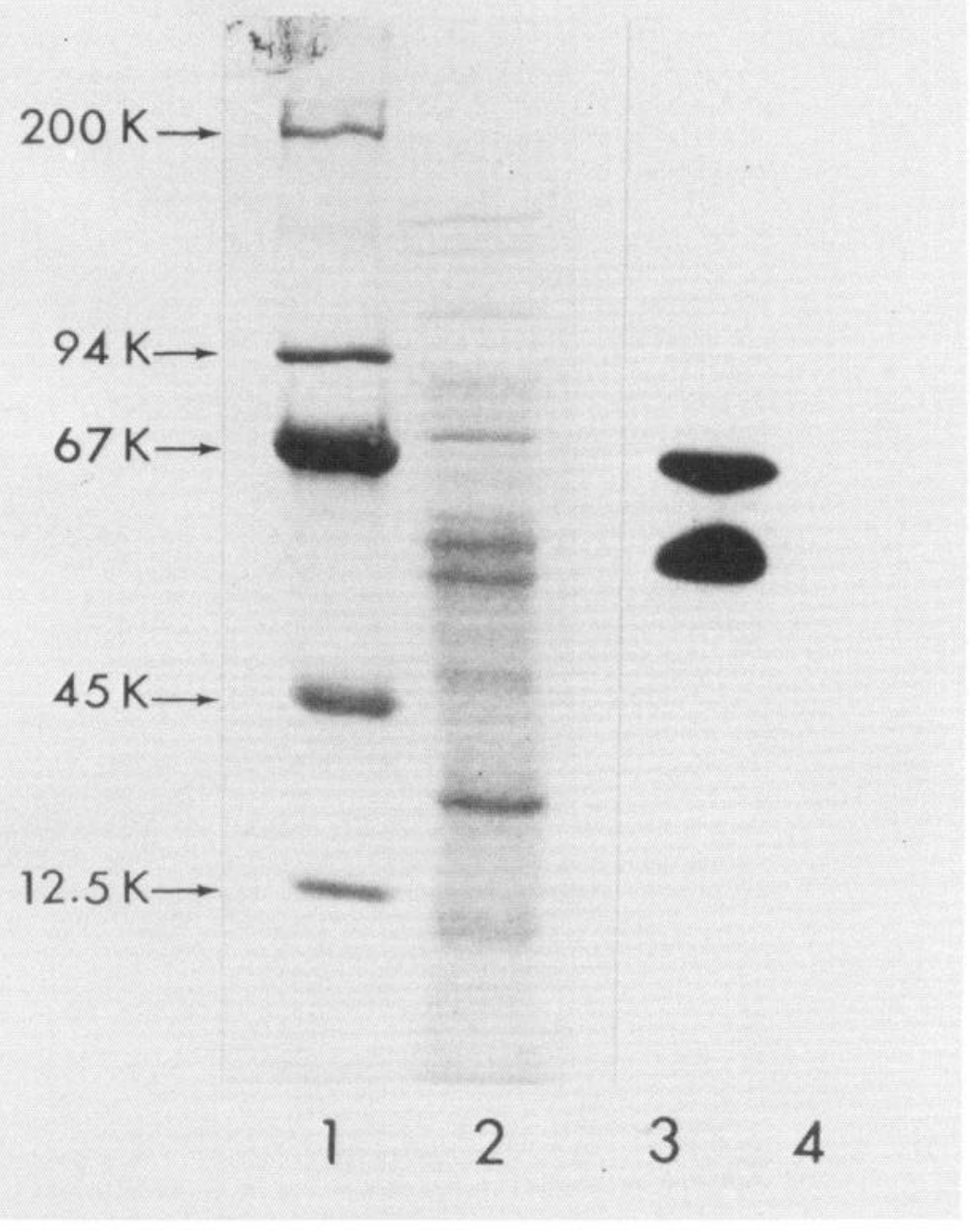

Figure 6. Western blot of DEAE-purified Canton S ChAT using a monoclonal anti-ChAT antibody. Lanes 1 and 2 are the Coomassie blue-stained $10 \%$ polyacrylamide gel, and lanes 3 and 4 are the radioautograph (18-hr exposure) of a nitrocellulose replica of the gel stained as described under "Materials and Methods." Lane 1 shows molecular weight standards with $M_{r}$ indicated in kilodaltons $(K)$. Lane 2 is the sample $(20 \mu \mathrm{l})$ of DEAE-purified ChAT estimated to contain $0.2 \mathrm{mg}$ of ChAT protein based on a final specific activity for pure Drosophila ChAT of $500 \mu \mathrm{mol} \cdot \mathrm{min}^{-1}$. $\mathrm{mg}$ (Slemmon et al., 1982). Lane 3 is the replica of lane 2, and lane 4 is the replica of lane 1 after transfer to nitrocellulose and staining with anti-Drosophila ChAT antibody 1 G4 (Crawford et al., 1982). The two bands staining in lane 3 have an $M_{r}=67 \mathrm{~K}$ and $54 \mathrm{~K}$. No bands were observed to stain when the monoclonal anti-ChAT antibody was eliminated from the incubation sequence or when an irrelevant monoclonal antibody of the same lgG subclass was substituted for the anti-ChAT antibody (data not shown). Neither band detected by antibody staining in lane 3 was visible by Coomassie staining of lane 2. ChAT represents less than $0.8 \%$ of the total protein at this stage of purification.

Chats and $\mathrm{Cha}^{t s 2}$ mutant heads. Both parameters increased about $15 \%$ in Canton $\mathrm{S}$ flies held at $32^{\circ} \mathrm{C}$ for $24 \mathrm{hr}$ when compared to flies held at $18^{\circ} \mathrm{C}$. In contrast, there was a progressive decrease in ChAT and $\mathrm{ACh}$ levels in both $\mathrm{Cha}^{t s 1}$ and $\mathrm{Cha} \mathrm{a}^{t s 2}$ mutants held at $32^{\circ} \mathrm{C}$. The values decreased for both parameters, about $50 \%$ for $\mathrm{Cha}^{t s 1}$ and $75 \%$ for $\mathrm{Cha}^{t \mathrm{~s} 2}$ after $24 \mathrm{hr}$ at $32^{\circ} \mathrm{C}$. Note also that $\mathrm{Cha}^{t s 1}$ and $\mathrm{Cha}^{t \mathrm{~s} 2}$ have $25 \%$ and $50 \%$ less ChAT and ACh initially than do wild type flies. Figure 2 shows data from another experiment in which ACh and choline levels were measured in individual fly heads under the same conditions as in Figure 1. In addition, the recovery of $\mathrm{ACh}$ levels to their control values were seen after holding flies at $32^{\circ} \mathrm{C}$ for $12 \mathrm{hr}$ and then transferring them back to $18^{\circ} \mathrm{C}$ for $12 \mathrm{hr}$. ChAT activity also recovered to control levels (data not shown). The temperature-induced changes in ACh and ChAT are thus reversible after $12 \mathrm{hr}$ at $32^{\circ} \mathrm{C}$. In contrast to the changes observed for ACh levels and ChAT activity, choline levels did not show a predictable change when flies were held at $32^{\circ} \mathrm{C}$ for 12 or $24 \mathrm{hr}$. Choline levels increased $30 \%$ to $40 \%$ in Canton S and $\mathrm{Cha}^{t s 2}$ flies held at $32^{\circ} \mathrm{C}$ for $12 \mathrm{hr}$ and in $\mathrm{Cha}^{t s 1}$ flies held at $32^{\circ} \mathrm{C}$ for $24 \mathrm{hr}$. Choline levels at other times appeared to remain unchanged from flies held exclusively at $18^{\circ} \mathrm{C}$.

In Figure 3 the combined data for ChAT, ACh, and choline were tested for correlation. A strong linear correlation was observed for ChAT versus ACh $(r=0.992)$, whereas no significant correlation was found for ChAT versus choline $(r=0.450)$ or choline versus ACh $(r=0.372)$. The correltion between ACh and ChAT activity held over a range of 8 - to 10 -fold variation for both parameters.
ChAT activity thus appears to be a good predictor of ACh levels in Drosophila heads, whereas choline levels are not.

$A C h E$. The levels of AChE were also determined in flies under conditions identical to those in Figure 2. No change in AChE activity was observed for wild type or Cha mutant flies in any group, except for a $30 \%$ decrease in AChE activity for $\mathrm{Cha}^{t s 2}$ flies held at $32^{\circ} \mathrm{C}$ for $24 \mathrm{hr}$. Variable AChE activity thus is not likely to account for the increased $\mathrm{ACh}$ levels observed in Canton S flies held at $32^{\circ} \mathrm{C}$ for 12 and $24 \mathrm{hr}$ or, more importantly, for the decreased levels of ACh seen in both Cha mutants.

Behavioral abnormalities. As noted by Greenspan (1980), mutant Cha flies raised at elevated temperature showed the behavioral abnormality of paralysis. This paralysis could be related to the levels of ACh or ChAT activity in the flies after shifting them to the restrictive temperature. After $12 \mathrm{hr}$ at $32^{\circ} \mathrm{C}, 14$ of $20 \mathrm{Cha}^{t s 2} / \mathrm{Cha}^{t s 2}$ flies showed abnormal movements similar to those described by Greenspan (1980), whereas all $\mathrm{Cha}^{\text {ts2 }}$ flies were paralyzed after $24 \mathrm{hr}$ at $32^{\circ} \mathrm{C}$. The Cha ${ }^{t s 1} / C a^{t s 1}$ flies showed no abnormal movements after $12 \mathrm{hr}$ at $32^{\circ} \mathrm{C}$, whereas 16 of 22 were paralyzed after $24 \mathrm{hr}$. Of $12 \mathrm{Cha}^{\mathrm{ts} 2} /$ $\mathrm{Cha}^{t s 2}$ flies grown initially at $32^{\circ} \mathrm{C}$ for $12 \mathrm{hr}$ and then shifted to $18^{\circ} \mathrm{C}$ for $12 \mathrm{hr}, 10$ recovered completely, whereas 2 flies were still partially paralyzed (i.e., legs were moving but flies were not walking or flying). The paralytic behavioral abnormalities thus seem to be present when ACh levels drop below 7 or 8 pmol/head.

Kinetic constants for ChAT. We have determined the Michaelis constants for both substrates of ChAT. The values are shown in Table I. Canton S and Cha ${ }^{t s 1}$ have similar $K_{m}$ values for both choline and acetyl-CoA. Chats2 shows $K_{m}$ 's of approximately one-half the 


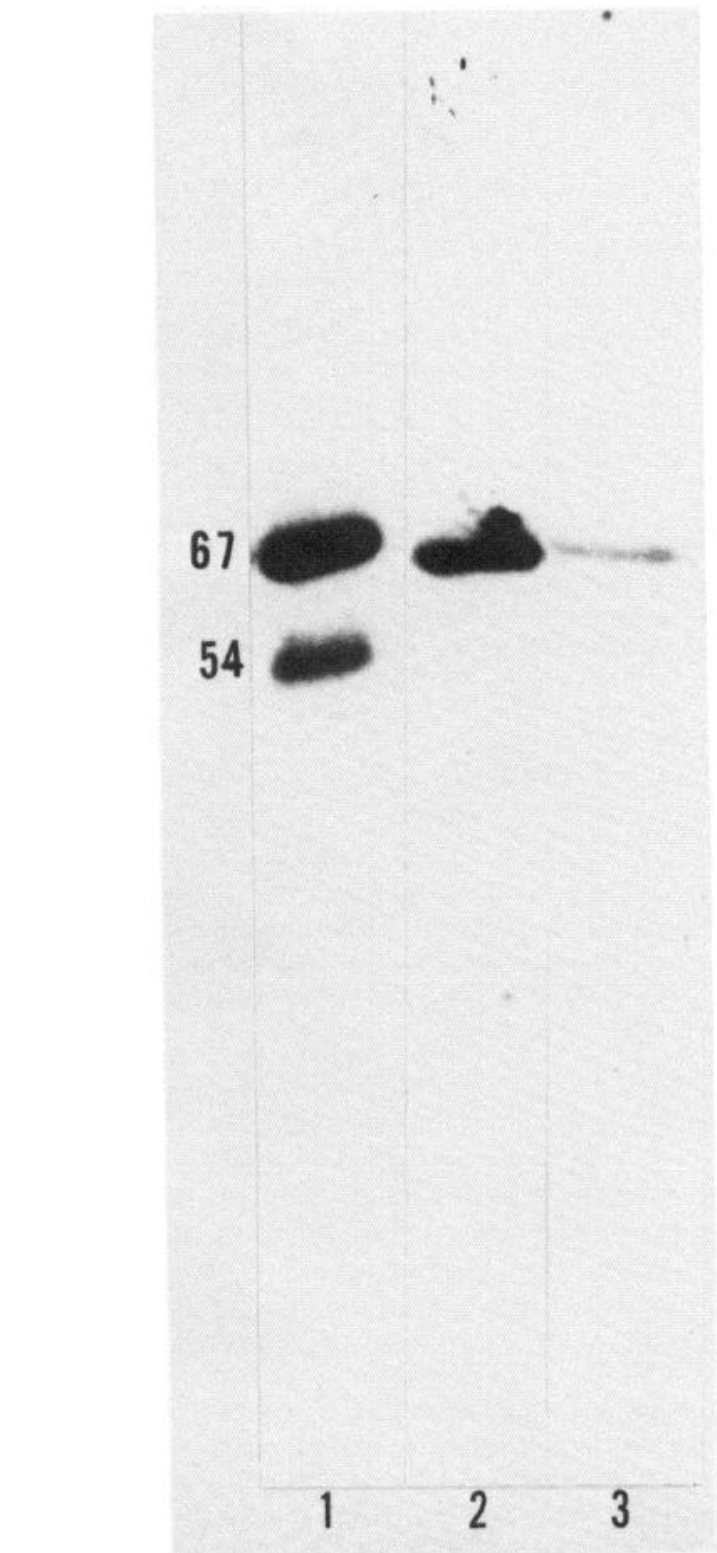

Figure 7. Western blot of wild type and mutant ChAT. Redissolved polyethylene glycol precipitates of ChAT (Slemmon et al., 1982) were electrophoresed in a $10 \%$ polyacrylamide gel. The gel was blotted onto nitrocellulose and stained with monoclonal anti-ChAT antibody 1 C8 (Crawford et al., $1982)$ and $\left[{ }^{125}\right]$ protein $A$ as described under "Materials and Methods." Samples were calculated to contain $32 \mathrm{ng}$ of Canton S (lane 1) or Cha ${ }^{t s 1}$ ChAT (lane 2) and $1 \mathrm{ng}$ of Cha ${ }^{\text {ts2 }}$ ChAT (lane 3) based on a final specific activity of $500 \mu \mathrm{mol} \cdot \mathrm{min}^{-1} \cdot \mathrm{mg}^{-1}$ for pure ChAT and correcting for temperature inactivation during assay. The molecular weight of the stained bands was determined from the same molecular weight standards used in Figure 6. The radioautograph was exposed for $18 \mathrm{hr}$.

values for Canton $\mathrm{S}$ and $\mathrm{Cha}^{t s 1}$ for both substrates. Cha ${ }^{t s 1}$ thus appears kinetically similar to the wild type enzyme, whereas $C h a^{t s 2}$ appears to be a slightly more efficient enzyme.

Isoelectric focusing. We have previously reported two isoelectric focusing forms for partially purified Canton S ChAT (Slemmon et al., 1982). Figure 4 shows the results of isoelectric focusing on freshly prepared homogenate of Canton $\mathrm{S}$ flies and compares this pattern to the pattern observed for ChAT from both Chats mutants. Canton $\mathrm{S}$ has two distinct isoelectric forms, whereas $C h a^{t s 1}$ shows only a single form. Isoelectric focusing of $\mathrm{Ch}^{\text {ts }}$ most often showed the pattern seen in Figure $4 d$, with a major and minor form, similar to wild type pattern, but with both forms shifted to a higher pl. In three experiments only the lower $\mathrm{pl}$ form was observed for $\mathrm{Ch} \mathrm{a}^{\mathrm{ts} 2}$. The reason for these variable results with $C h a^{t s 2}$ is unknown. Table \| summarizes the pl's observed in a number of focusing experiments in which different sample or $\mathrm{pH}$ gradients were used. Samples included homogenates or polyethylene glycol-precipitated ChAT and were prepared fresh or frozen at $-20^{\circ}$ or $-80^{\circ} \mathrm{C}$ for 1 day or 3 weeks. Samples were also focused on $\mathrm{pH} 4$ to 6 gradients or $\mathrm{pH} 3$ to 10 gradients. In general, no systematic differences were observed in the pl's or relative amounts of ChAT activity recovered for each $\mathrm{pl}$ form, with the exception of the occasional absence of any detectable higher $\mathrm{pl}$ form for $\mathrm{Ch}^{t s 2}$ (three of seven experiments).

In vitro thermolability of high and low pl forms of ChAT. Since $C h a^{t s 1}$ showed a pl similar to the high pl form of Canton $\mathrm{S}$, the thermolability of the different pl forms of ChAT was tested after separating them by thin layer polyacrylamide isoelectric focusing. As shown in Figure 5, no significant differences were observed for the temperature lability of the high and low pl forms of Canton S or $\mathrm{Cha}^{\text {ts2 }}$ ChAT. In addition, no differences were noted in the temperature inactivation of $C h a^{t s 1} \mathrm{ChAT}$ sampled from the high and low $\mathrm{pH}$ region of the single ChAT pl form. Different pl forms of ChAT thus have no effect on the in vitro thermolability of the enzyme.

Immunoblot analysis of ChAT. We have determined the polypeptides reacting with a monoclonal anti-ChAT antibody (Crawford et al., 1982) by Western blot analysis (Towbin et al., 1979). Figure 6 shows polypeptides staining with antibody at 67,000 and 54,000 daltons for DEAE-purified (Slemmon et al., 1982) Canton S ChAT. Neither band was visible in the Coomassie blue-stained gel of this sample. These two bands correspond in molecular weight to two of the polypeptides we have identified as structurally related proteins in highly purified Drosophilia ChAT (Slemmon et al., 1982). A third polypeptide at 13,000 daltons present in pure ChAT is not stained by the monoclonal antibody. Since this antibody will directly inhibit ChAT activity, it most probably is recognizing an epitope at or near the active sight of the enzyme. The 67,000 - and 54,000-dalton proteins therefore probably contain the catalytic site.

Figure 7 shows the results of an immunoblot analysis of redissolved polyethylene glycol precipitates of ChAT from Canton $\mathrm{S}$ and both $\mathrm{Cha}^{t s}$ mutants. Note that only one band at 67,000 daltons was detected for either $\mathrm{Cha}^{t s}$ mutant in contrast to two polypeptides $(67,000$ and 54,000$)$ for Canton S ChAT. For this gel, an equal amount of ChAT protein, calculated by activity, was electrophoresed for Canton S and $C{ }^{t s 1}$, whereas 16 -fold less ChAT protein was applied for the $\mathrm{Cha}^{\mathrm{ts} 2}$ mutants to avoid overloading the gel. The polypeptide pattern observed for $C a^{t s}$ is clearly different from wild type by the absence of any detectable 54,000-dalton protein, whereas $C h a^{t s 2}$ is apparently different from wild type. The presence of a 54,000-dalton component in Cha ${ }^{t s 2}$ cannot be ruled out definitively at this time since a smaller amount of ChAT had to be electrophoresed to prevent overloading of the gel with non-ChAT proteins.

\section{Discussion}

We have taken advantage of two temperature-sensitive ChAT mutants described initially by Greenspan (1980) to manipulate ChAT activity in vivo in adult Drosophila melanogaster and to relate ChAT activity to neurotransmitter levels. An increase in ChAT activity for wild type Canton $\mathrm{S}$ flies or a decrease for either ts mutant was observed for flies reared at $32^{\circ} \mathrm{C}$ rather than $18^{\circ} \mathrm{C}$. Surprisingly, a very strong correlation was observed between ChAT activity and ACh levels. This correlation held over an 8- to 10-fold variation in the absolute amounts of enzyme activity or transmitter content. ChAT activity may thus be an important regulatory and/or rate-limiting step for in vivo ACh synthesis. Choline levels did not vary in any regular pattern with respect to either ChAT activity or ACh levels. Thus, the steady-state choline level per se does not seem to participate in the regulation of $\mathrm{ACh}$ synthesis in Drosophila under the conditions of our experiments. Our observations are in contrast to most studies of the relationship of ChAT activity to ACh levels in vertebrate 


\section{Proposed model for Drosophila ChAT}

\section{Native ChAT}

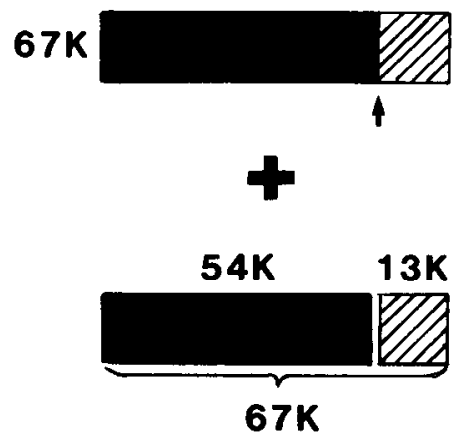

Denatured ChAT

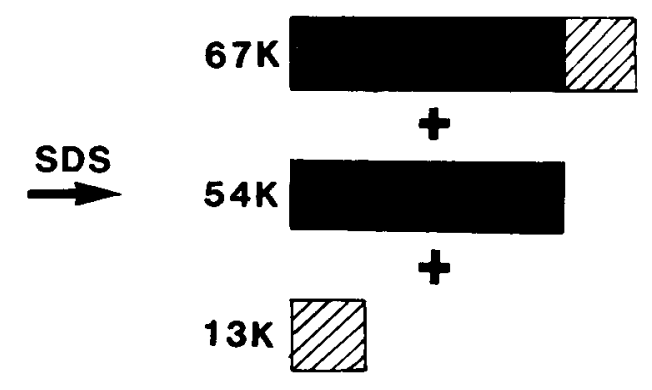

Figure 8. Proposed structural model for Drosophila ChAT. Native wild type enzyme exists in two forms. One is a single chain 67-kilodalton $(K)$ polypeptide and the other is a noncovalent complex of a 54- and 13kilodalton polypeptide which could have been generated by a post-translational event (limited proteolysis) occurring at the arrow. These two forms represent different pl forms of ChAT. In SDS-denatured ChAT the 67- and 54-kilodalton peptides stain with active sitedirected antibody (solid bars) which should thus contain both the antibody-binding epitope and the enzymeactive site. nervous system (for review, see Jope, 1979). In these other studies, it has been argued that ChAT activity is far in excess of that necessary to regulate the steady-state levels of ACh (Hebb, 1972; Tucek, 1983). High affinity choline transport into nerve endings seems to represent the key regulatory site for $A C h$ production in several of these other studies (Kuhar and Murrin, 1978). Since we have not directly measured the high affinity choline transport, we cannot directly rule out its significance as a regulatory step in Drosophila ACh production. Perhaps the difference between our results and the conclusions reached by others reflects species difference or differences in the specific procedures used to manipulate various potential control sites for $A C h$ production. One obvious difference between our experimental paradigm and those of the other studies is that we rely on no exteral pharmacological manipulation of uncertain specificity to alter ChAT activity. In our analysis temperature is used as the only procedure to alter ChAT activity. Temperature-dependent alteration in ChAT activity may be relatively specific since we have observed no change in AChE, another important ACh-metabolizing enzyme present in Drosophila. Other studies which have sought to inhibit ChAT activity by administering an exogenous ChAT inhibitor (Krell and Goldberg, 1975) have been criticized for their failure to adequately detail side effects of such treatment on AChE activity and/or use-dependent changes in ACh synthesis and release.

Several interesting features of ACh metabolism and utilization in Drosophila deserve comment. The heads of this organism contain the highest reported levels of ChAT activity for any biological source. It may be that in Drosophila, and possibly other insects, the numbers of neural elements using ACh are relatively greater than those using other neurotransmitters. We have recently observed the immunocytochemical distribution of ChAT in Drosophila CNS (K. Ikeda and P. M. Salvaterra, unpublished observation). The pattern of staining appears to be especially intense in the neuropil of the visual ganglia and other sensory areas such as the antennal complex. This distribution lends support to the long held suspicion that ACh may be a primary sensory neurotransmitter in arthropods. Although ACh synthesis and release have recently been studied in Drosophila larvae (Wu et al., 1983), the absolute levels of ACh and choline were not reported. In the present study $A C h$ levels were found to vary from about 20 to $40 \mathrm{pmol} / \mathrm{head}$. Since a Drosophila head weighs approximately $0.1 \mathrm{mg}$, the concentration of ACh would be between 200 and $400 \mathrm{nmol} / \mathrm{gm}$ of tissue, or approximately $0.5 \mathrm{~mm}$. This level of $\mathrm{ACh}$ is among the highest reported values for tissue ACh concentration and is one or two orders of magnitude higher than the ACh levels reported for vertebrate CNS (Saelens and Simke, 1976). In fact, this level of ACh is similar to the concentration of ACh reported for isolated individual cholinergic somata from various invertebrates (McCaman and McCaman, 1976). The levels of ACh and choline are about equal in Drosophila heads. The ratios of choline to ACh in vertebrate nervous system have been reported to vary from $1: 1$ to nearly $10: 1$, depending on the assay, sacrifice, or analysis methods used. In addition, distinct brain regional differences in this ratio have been noted in vertebrates (Saelens and Simke, 1976). Perhaps this reflects the concentration of cholinergic neurons and/or endings in a given region. Choline would be expected to be in all regions of the brain in which it serves its other functional roles not related to neurotransmission, such as phospholipid synthesis. ACh would be expected to be only in brain regions containing cholinergic neurons. It should also be noted that the ratio of ACh to choline has been reported to be $1: 1$ in individual cholinergic somata (McCaman and McCaman, 1976).

We have recently proposed a model for purified Drosophila ChAT (Slemmon et al., 1984) which is summarized diagrammatically in Figure 8 . In this model the single structural gene for ChAT (Greenspan, 1980) would code for the synthesis of a single chain polypeptide with $M_{\mathrm{r}}=67,000$. This 67,000 dalton polypeptide would then undergo post-translational modification by limited proteolysis to generate another form of the enzyme activity consisting of two noncovalently complexed polypeptides with $M_{r}=54,000$ and 13,000 . Similar tryptic peptides present in all three polypeptides in purified ChAT strongly support this model (Slemmon et al., 1984). In the present study we have presented evidence that both the 67,000 and 54,000-dalton polypeptides present in Canton S ChAT stain with a monoclonal antibody that directly inhibits the enzyme activity. This observation is consistent with the notion that the single-chain 67,000 dalton ChAT and the noncovalent complex of $54,000+13,000$ daltons are both enzymatically active and most likely represent the two different pl forms we have observed for wild type Canton $S$ ChAT. Unfortunately, we have not been able to establish this point more directly by running two-dimensional gels since isoelectric focusing interferes with the ability of our monoclonal antibodies to recognize ChAT.

Greenspan (1980) has presented evidence that only one gene is present for ChAT in Drosophila; therefore, a post-translational modification is likely to account for multiple pl forms. Further support for this hypothesis is the absence of any detectable 54,000-dalton antibody-staining component in the $C h a^{t s 1}$ mutant and the presence of only a single detectable $\mathrm{pl}$ form for $C h \mathrm{a}^{t s 1}$. We would thus predict that the mutation in Cha ${ }^{t s 1}$ is a replacement of the particular amino acid residue where proteolysis occurs in wild type ChAT. Although the nature of the Cha ${ }^{t s 1}$ mutation confers thermolability on the ChAT protein that is produced, lack of proteolytic processing does not in itself lead to a thermolabile enzyme since no differences were noted in the temperature inactivation of the different $\mathrm{pl}$ forms of ChAT. As mentioned under "Results," the sensitivity of our immunoblot analysis may not have been adequte to detect the presence of a 54,000 - 
dalton component in Cha ${ }^{t s 2}$. The significance of the proposed limited proteolysis for ChAT function remains unknown. We are attempting to isolate the gene for ChAT from Drosophila, and once this is accomplished, it will be possible to perform direct tests on the functional significance of proteolysis.

In summary, we have taken advantage of the production of two temperature-sensitive Cha gene mutants to investigte ACh metabolism in vivo and to study the structural and biochemical properties of the mutant ChAT gene products. The existence of these conditional mutants makes it possible to regulate neurotransmitter production in a direct and specific manner and should be useful for a variety of future biochemical and physiological studies of ACh metabolism and cholinergic processes by allowing them to come under experimental genetic control (Hall and Greenspan, 1979; Hall et al., 1979).

\section{References}

Barker, L. A., and T. W. Mittag (1975) Comparative studies of substrates and inhibitors of choline transport and choline acetyltransferase. J. Pharmacol. Exp. Ther. 192: 86-94.

Cohen, E. L., and R. J. Wurtman (1975) Brain acetylcholine: Increase after systemic choline administration. Life Sci. 16: 1095-1102.

Collier, B., Y. N. Kwok, and S. A. Welner (1983) Increased acetylcholine synthesis and release following presynaptic activity in a sympathetic ganglion. J. Neurochem. 40: 91-98.

Crawford, G. D., J. R. Slemmon, and P. M. Salvaterra (1982) Monoclonal antibodies selective for Drosophila melanogaster choline acetyltransferase. J. Biol. Chem. 257: 3853-3856.

Dewhurst, S. A., R. E. McCaman, and W. D. Kaplan (1970) The time course of development of acetylcholinesterase and choline acetyltransferase in Drosophila melanogaster. Biochem. Genet. 4: 499-508.

Ellman, G. L., K. D. Courtney, V. Adres, and R. M. Featherstone (1961) A new and rapid colorimetric determination of acetylcholinesterase activity. Biochem. Pharmacol. 7: 88-95.

Fonnum, F. (1975) A rapid radiochemical method for the determination of choline acetyltransferase. J. Neurochem. 24: 407-409.

Gerschenfeld, H. M. (1973) Chemical transmission in invertebrate central nervus systems and neuromuscular junctions. Physiol. Rev. 53: 1-119.

Glover, V. A. S., and L. T. Potter (1971) Purification and properties of choline acetyltransferase from ox brain striate nuclei. J. Neurochem. 18: 571-580.

Goldberg, A. M., and R. E. McCaman (1973) The determination of picomole amounts of acetylcholine in mammalian brain. J. Neurochem. 20:1-8.

Goldberg, A. M., and R. E. McCaman (1974) An enzymatic method for determination of picomole amounts of choline and acetylcholine. In Handbook of Chemical Assay Methods, I. Hanin, ed., Raven Press, New York.

Gorczyca, M., and J. C. Hall (1983) Choline acetyltransferase mutations block activity at a chemical synapse in Drosophila melanogaster. Am. Soc. Neurochem. (Abstr.) 9:832.

Greenspan, R. J. (1980) Mutations of choline acetyltransferase and associated neural defects in Drosophila melanogaster. J. Comp. Physiol. 137: 83-92.

Guyenet, P., P. Lefresne, J. Rossier, J. C. Beaujouan, and J. Glowinski (1973a) Inhibition by hemicholinium -3 of $\left[{ }^{14} \mathrm{C}\right]$ acetylcholine synthesis and $\left[{ }^{3} \mathrm{H}\right]$ choline high affinity uptake in rat striatal synaptosomes. J. Mol. Pharmacol. 9: 630-639.

Guyenet, P., P. Lefresne, J. Rossier, J. C. Beaujouan, and J. Glowinski (1973b) Effect of sodium, hemicholinium-3 and antiparkinson drugs on $\left[{ }^{14} \mathrm{C}\right]$ acetylcholine synthesis and $\left[{ }^{3} \mathrm{H}\right]$ choline uptake in rat striatal synaptosomes. Brain Res. 62: 523-529.

Haga, T. (1971) Synthesis and release of $\left[{ }^{14} \mathrm{C}\right]$ acetylcholine in synaptosomes. J. Neurochem. 18: 781-798.

Hall, J. C., and R. J. Greenspan (1979) Genetic analysis of Drosophila neurobiology. Annu. Rev. Genet. 13: 127-195.

Hall, J. C., R. J. Greenspan, and D. R. Kankel (1979) Neural defects induced by genetic manipulation of acetylcholine metabolism in Drosophila. In
Society for Neuroscience Symposia. Vol. 4: Aspects of Developmental Neurobiology, pp. 1-42, Society for Neuroscience, Bethesda, MD.

Hanbrich, D. R., and T. J. Chippendale (1977) Regulation of acetylcholine synthesis in nervous tissue. Life Sci. 20: 1465-1478.

Hebb, C. (1972) Biosynthesis of acetylcholine in nervous tissue. Physiol. Rev. 52: 918-957.

Jope, R. S. (1979) High affinity choline transport and acetyl CoA production in brain and their roles in the regulation of acetylcholine synthesis. Brain Res. Rev. 1: 313-344

Jope, R. S., and D. J. Jenden (1977) Synaptosomal transport and acetylation of choline. Life Sci. 20: 1389-1392.

Jope, R. S., and D. J. Jenden (1979) Choline and phospholipid metabolism and the synthesis of acetylcholine in rat brain. J. Neurosci. Res. 4: 69-82.

Kaita, A. A., and A. M. Goldberg (1969) Control of acetylcholine synthesis: Inhibition of choline acetyltransferase by acetylcholine. J. Neurochem. 16 . 1185-1191.

Klemm, N. (1976) Histochemistry of putative transmitter substances in the insect brain. Prog. Neurobiol. 7: 99-169.

Krell, R. D., and A. M. Goldberg (1975) Effect of choline acetyttransferase inhibitors on mouse and guinea pig brain choline and acetylcholine. Biochem. Pharmacol. 24: 391-396.

Kuhar, M. J., and L. C. Murrin (1978) Sodium-dependent, high affinity choline uptake. J. Neurochem. 30: 15-21.

Laemmli, U. K. (1970) Cleavage of structural proteins during the assembly of the head of bacteriophage T4. Nature 277: 680-685.

Marchbanks, R. M., and P. D. Kessler (1982) The independency of choline transport and acetylcholine synthesis. J. Neurochem. 39: 1424-1433.

McCaman, R. E., and M. W. McCaman (1976) Biology of individual cholinergic neurons in the invertebrate CNS. In Biology of Cholinergic Function, A. M. Goldberg and I. Hanin, eds., pp. 485-513, Raven Press, New York.

McCaman, R. E., and J. Stetzler (1977) Radiochemical assay for ACh: Modifications for sub-picomole measurements. J. Neurochem. 28: 669671.

Morris, D., A. Maneckjee, and C. Hebb (1971) The kinetic properties of human placenta choline acetyltransferase. Biochem. J. 125: 857-863.

Pitman, R. M. (1971) Transmitter substances in insects: A review. Comp. Gen. Pharmacol. 2: 347-371.

Saelens, J. K., and J. P. Simke (1976) Appendix III: Acetylcholine and choline concentrations in various biological tissues. In Biology of Cholinergic Function, A. M. Goldberg and I. Hanin, eds., pp. 661-682, Raven Press. New York.

Salvaterra, P. M., and R. E. McCaman (1984) Acetylcholine levels and choline acetyltransferase activity in Drosophila. Trans. Am. Soc. Neurochem. (Abstr.) 15: 169

Salvaterra, P. M., G. D. Crawtord, and L. Correa (1983) Isoelectric focusing and immunoblot staining of Drosophila choline acctyltransferase. Am. Soc. Neurosci. (Abstr.) 9: 74

Slemmon, J. R., P. M. Salvaterra, G. Crawtord, and E. Roberts (1982) Purification of choline acetyltransferase from Drosophila melanogaster. J. Biol. Chem. 257: 3847-3852.

Slemmon, J. R., P. M. Salvaterra, and E. Roberts (1984) Molecular characterization of choline acetyltransferase from Drosophila melanogaster. Neurochem. Int., in press.

Suszkiw, J. B., and G. Pilar (1976) Selective localization of a high affinity choline uptake system and its role in ACh formation in cholinergic nerve terminals. J. Neurochem. 26: 1133-1138.

Towbin, H., T. Staehelin, and J. Gordon (1979) Electrophoretic transfer of proteins from polyacrylamide gels to nitrocellulose sheets: Procedure and some applications. Proc. Natl. Acad. Sci. U. S. A. 76: 4350-4354

Tuček, S. (1983) The synthesis of acetylcholine. In Handbook of Neurochemistry, Ed. 2, A. Laitha, ed., Vol. 4, pp. 219-249, Plenum Press, New York.

Wecker, L., and D. E. Schmidt (1979) Central cholinergic function: Relationship to choline administration. Life Sci. 25: 375-384.

Wu, C. - F, J. M. Berneking, and D. L. Barker (1983) Acetylcholine synthesis and accumulation in the CNS of Drosophila larvae: Analysis of shibire ${ }^{i s}$, a mutant with a temperature-sesnsitive block in synaptic transmission. J. Neurochem. 40: 1386-1396.

Yamamura, H. I., and S. H. Snyder (1973) High affinity transport of choline into synaptosomes of rat brain. J. Neurochem. 21 : 1355-1374 